\title{
257. LIMOSELLA AQUATICA L. EN LA COMUNIDAD DE MADRID
}

\author{
Leopoldo MEDINA ${ }^{1}$, Patricia BARBERÁ ${ }^{1}$, Antoni BUIRA ${ }^{1}$, \\ Francisco Javier TOMÉ$^{2} \&$ Carlos $\mathrm{AEDO}^{1 *}$
}

Recibido el 26 de Junio de 2015, aceptado para su publicación el 8 de julio de 2015

\section{Limosella aquatica L. in Madrid región (Spain)}

Palabras clave. Scrophulariaceae, Limosella aquatica, Madrid, España.

Key words. Scrophulariaceae, Limosella aquatica, Madrid, España.

Limosella aquatica L., Sp. P1.: 631 (1753)

ESPAÑA, MADRID: Madrid, Monte de El Pardo, recula del Embalse del Pardo en el Puente de las Tablas, $40^{\circ} 35^{\prime} 50^{\prime \prime} \mathrm{N}, 03^{\circ} 48^{\prime} 14^{\prime}$ 'W, 630 $\mathrm{m}$, borde del embalse, 16-VI-2015, C. Aedo, P. Barberá, A. Buira, M. Dueñas, L. Medina \& F.J. Tomé CA23071 (MA 892370)

Limosella aquatica L. es un taxon de distribución circumboreal (Sánchez, 2008) que en la Península Ibérica se encuentra dispersa por el cuadrante noroccidental (ANTHOS, 2015). En la provincia de Madrid había sido citada en el siglo XVIII por J. Quer (cf. Gómez Ortega, 1784: 172) bajo el polinomio Ranunculus aquaticus, Plantaginis folio, angustissimo, "en las aguas pantanosas, encharcadas y cenagosas de los prados de Soto Luzon, y en su contorno. La he visto también con mucha abundancia en las aguas detenidas, y balsas del Real Sitio de S. Lorenzo del Escorial". Colmeiro (1849: 112; 1888: 224), Cutanda (1861: 513) y Lange (1870: 592) recogen las citas de Quer sin añadir novedades en Madrid. No existen desde estas primeras referencias, otras citas que confirmen la presencia de esta planta en el territorio de la Comunidad de Madrid. La síntesis de Flora iberica (Sánchez, 2008) recoge la provincia de Madrid con duda, sobre la base de la recopilación de Lange (1870). Las plantas de J. Quer, que se conservan en el herbario del Conservatoire et Jardin botaniques de la Ville de Genève, contienen unas etiquetas en las que no se menciona la localidad, por lo que sería muy difícil establecer un vínculo inequívoco con alguna de las localidades mencionadas. No obstante, las detalladas indicaciones descriptivas del botánico catalán apuntan a que sus citas de Limosella son fidedignas.

Las localidades madrileñas mencionadas por Quer de El Escorial corresponden posiblemente a las charcas de la zona de la actual Herrería o Casita del Príncipe, donde no ha vuelto a ser encontrada, y la del Soto de Luzón a los márgenes del río Manzanares en la zona del actual nudo Sur de la M-30 (Martín de López, 1846: 3), enclave totalmente alterado en la actualidad.

En el herbario del Real Jardín Botánico se conserva un pliego (MA 330343) asignado inicialmente a la provincia de Madrid y perteneciente al herbario de Cavanilles, con una etiqueta manuscrita del botánico valenciano en la que se lee "D. Pascal misit. 1803". Este material, cuya procedencia es difícil de establecer con certeza, fue enviado por Diego Baldassarre-Pascal (1768-1812), botánico italiano que trabajaba en Parma y que mantenía relaciones epistolares con Cavanilles (Affó, 
1833: 647; San Pio \& Collar, 1995: 229). En todo caso no hay ningún indicio que permita suponer que se trata de una planta ibérica.

En junio de 2015, en una visita de prospección al Monte del Pardo, encontramos abundantes poblaciones de esta planta en los márgenes del embalse de El Pardo, donde aparece formando comunidades casi monoespecíficas, apenas con Juncus pygmaeus Thuill. Estas comunidades se encuentran cubriendo las pocetas laterales al cauce embalsado del Manzanares, sobre suelos muy limosos y que quedan al descubierto al bajar el nivel del agua de la zona embalsada. Estos medios y sus comunidades son semejantes, aunque algo más pobres, a las indicadas por Ladero (1975) para esta especie en Extremadura oriental.

AGRADECIMIENTOS. A Alicia Pastor, Juan Carlos de la Mata y Ángel Muñoz, de Patrimonio Nacional, por su colaboración y las facilidades ofrecidas para la visita al Monte de El Pardo.

\section{BIBLIOGRAFÍA}

AFFÓ, I. -1833- Memorie degli scrittori e letteratii parmigiani raccolte dal Padre Ireneo Affó e continuate da Angelo Pezzana, vol. 7. Dalla Ducale Tipografia, Parma.

ANTHOS -2015- Sistema de información de las plantas de España. Real Jardín Botánico, CSICFundación Biodiversidad. Recurso electrónico en www.anthos.es. Consulta realizada en junio de 2015.

COLMEIRO, M. -1849-Apuntes para la flora de las dos Castillas. Librería de Angel Calleja, Madrid.

COLMEIRO, M. -1888- Enumeración y revisión de las plantas de la Península Hispano-Lusitana é islas Baleares [...], vol. 4. Imprenta de la viuda é hija de Fuentenebro, Madrid.

CUTANDA, V. -1861-Flora compendiada de Madrid y su provincia. Imprenta Nacional, Madrid.

GÓMEZ ORTEGA, C. -1784- Continuacion de la flora Española, ó historia de las plantas de
España, que escribia Don Joseph Quer [...], vol. 6. Imprenta Joachin Ibarra, Madrid.

LADERO, M. -1975- Limosella aquatica L. (Scrophulariaceae) en Extremadura. Anales Jard. Bot. Madrid 32: 1489-1491.

MARTÍN DE LÓPEZ, P. -1846- Catálogo de todas las calles y plazas, parroquias, iglesias $y$ establecimientos públicos más notables de Madrid. Sociedad Tipográfica de Hortelano y Compañía, Madrid.

SAN PÍO, M.P. \& P. COLLADO -1995- El archivo de A.J. Cavanilles en el Real Jardín Botánico. Asclepio 47: 217-240.

SÁNCHEZ, J. -2008- Limosella L. In S. Castroviejo et al. (eds). Flora iberica 13: 338-340. Real Jardín Botánico, Madrid.

LANGE, J. -1870- Limosella L. In M. Willkomm \& J. Lange. Prodromus florae Hispanicae [...], vol. 2: 592-593. Sumtibus E. Schweizerbart, Stuttgart.

Dirección de los autores. 1 Real Jardín Botánico, CSIC, Plaza de Murillo 2, 28014 Madrid. 2 Patrimonio Nacional, Dirección de Inmuebles y Medio Natural, Servicio de Jardines y Montes, c/ Bailén s/n, 28071 Madrid.*Autor para correspondencia: aedo@rjb. csic.es 